\title{
Potential of curcumin-mediated photodynamic inactivation to reduce oral colonization
}

\author{
Carolina Santezi ${ }^{a}$, Juliane M.G. Tanomaru ${ }^{a}$, Vanderlei S. Bagnato ${ }^{\mathrm{b}}$, \\ Osmir B. Oliveira Júnior ${ }^{a}$, Lívia N. Dovigo ${ }^{\mathrm{a}, *}$ \\ a Araraquara Dental School, UNESP- Univ Estadual Paulista, Araraquara, SP 14801-903, Brazil \\ b Physics Institute of São Carlos, University of São Paulo (USP), São Carlos, SP 13566-250, Brazil
}

\section{A R T I C L E I N F O}

\section{Article history:}

Received 11 January 2016

Received in revised form 31 March 2016

Accepted 12 April 2016

Available online 23 April 2016

\section{Keywords:}

Biological contamination

Curcumin

Photochemotherapy

\begin{abstract}
A B S T R A C T
Objective: The present study assessed the susceptibility of salivary pathogens to photodynamic inactivation (PDI), mediated by a water-soluble mixture of curcuminoids (CRM) and LED light.

Methods: A $10 \mathrm{~mL}$ sample of unstimulated saliva was collected from volunteers. The inoculum was prepared using $9 \mathrm{~mL}$ of saline and $1 \mathrm{~mL}$ of saliva. Inoculum suspensions were divided into 14 groups and treated according to the description below. Groups that received the PDI treatment (light for 1 min or $5 \mathrm{~min}$ and $1.5 \mathrm{~g} / \mathrm{L}$ or $3.0 \mathrm{~g} / \mathrm{L}$ of $\mathrm{CRM}$ concentration) were called $\mathrm{C}_{1.5} \mathrm{~L}_{1.8}, \mathrm{C}_{1.5} \mathrm{~L}_{9.0}, \mathrm{C}_{3.0} \mathrm{~L}_{1.8}, \mathrm{C}_{3.0} \mathrm{~L}_{9.0}$. To evaluate the CRM decontamination alone, the $C_{1.5 / 1}, C_{1.5 / 5}, C_{3.0 / 1}$ and $C_{3.0 / 5}$ groups were assessed. Likewise, light alone was evaluated through the $\mathrm{L}_{1.8}$ and $\mathrm{L}_{9.0}$ groups. Chlorhexidine at $0.12 \%$ (CLX) for 1 or 5 min was used for the positive control groups ( $\mathrm{CLX}_{1}$ and $\mathrm{CLX}_{5}$, respectively); saline was used for 1 or $5 \mathrm{~min}\left(\mathrm{CTR}_{1}\right.$, $\mathrm{CTR}_{5}$, respectively) for the negative control groups. After the tests, serial dilutions were performed, and the resulting samples were plated on blood agar in microaerophilic conditions. The number of colony forming units $(\mathrm{CFU} / \mathrm{mL})$ was determined and $\log _{10}$-transformed. Data were analyzed using a One-way Analysis of Variance with Welch correction, followed by the Games Howell's test $(\alpha=0.05)$. Log reduction (LR) measure for antimicrobial efficacy was also calculated using data from the $\mathrm{CTR}_{5}$ as untreated samples.

Results: The $\mathrm{CHX}_{5}$ showed the best antimicrobial result, followed by the $\mathrm{CLX}_{1}$. The antimicrobial effect of CRM was more pronounced when associated with light (PDI), but significantly lower than the CLX effect. The $\mathrm{C}_{3.0} \mathrm{~L}_{9.0}$ protocol showed similar results to the $\mathrm{CLX}_{1}$.

Conclusion: The results show that PDI with CRM at the studied concentrations is as effective for oral decontamination in clinical dental care conditions as the CLX at $0.12 \%$ for $1 \mathrm{~min}$.
\end{abstract}

(C) 2016 Elsevier B.V. All rights reserved.

\section{Introduction}

The human mouth can host more than 700 species of pathogenic and non-pathogenic microorganisms [1]. Thus, the bacterial aerosols generated from a patient's mouth during dental procedures expose the dental staff to a chronic occupational hazard. The bioaerosol can spread by a radius of $60 \mathrm{~cm}$ from the oral cavity, contaminating everything in this perimeter [2]. Consequently, several infectious diseases, including those caused by viruses, can be transmitted by the aerosol representing significant health risks for the dental staff, such as chickenpox, hepatitis B, hepatitis A,

\footnotetext{
* Corresponding author at: Humaitá Street, 1680, Postal Code: 14801-903 Araraquara, SP, Brazil.

E-mail address: lidovigo@foar.unesp.br (L.N. Dovigo).
}

herpetic conjunctivitis, herpes simplex, herpes zoster, infectious mononucleosis, measles, rubella, mumps and influenza. Additionally, many other diseases may be caused by bacteria and fungi [3]. The bioaerosol can also put healthy patients at risk because of the possibility of cross-contamination at the dental office [1-5].

The biosafety manual recommends the routine use of personal protective equipment (PPE) as standard for the treatment of any patient [5]. However, there are reports showing that the aerosol formed by dental handpieces remains suspended in the environment for at least 10 min to a few hours after treatment [4,5]. In that case, the use of PPE will not guarantee the protection of the dental team. Therefore, measures that can effectively reduce the amount of microorganisms present in the oral aerosol should be incorporated as a biosafety routine associated with the use of PPE to ensure more effective protection of the dental staff and patients. For this 
purpose, some practitioners routinely ask the patient to perform oral decontamination using topical mouthwashes [6].

Currently, $0.12 \%$ chlorhexidine digluconate (CLX) is the most widely used antiseptic for mouth disinfection [7]. According to Davies [8], CLX is a broad spectrum antimicrobial agent that exhibits activity against gram-negative and gram positive bacteria and yeasts. However, there is no positive evidence of their effectiveness against spores [9] and the routine use of CLX as an antiseptic may cause alteration in taste sensation and staining of the teeth and tongue $[8,10]$. Because of its drawbacks, investigations have focused on the search for alternative methods for oral decontamination $[11,12]$. Therapy based on physical interaction of light and photosensitizing drugs, called photodynamic therapy (PDT), have been developed as an alternative or complementary technique to solve many microorganism-related health problems [12-16]. Photodynamic inactivation of microorganisms, also known as Photodynamic Antimicrobial Chemotherapy (PACT) [16] or Photodynamic Inactivation (PDI) [17], is based on the combination of a photosensitizer (PS) and light of the appropriate wavelength to excite the PS molecule [18]. The killing is a result of the formation of radicals and reactive oxygen species that can react with multiple targets at a cellular level. Thus, advantages of PDI include the few undesired side effects and the improbable chances of promoting resistance by microorganisms [14-19].

Different types of PS have been investigated in recent years [20-28]. Curcumin (CUR) is a phenolic compound, member of the curcuminoid family, which can be extracted from the rhizomes of Curcuma Longa. CUR has been traditionally used as a cooking spice [29], but several in vitro and in vivo investigations suggested that CUR has great therapeutic potential, including anti-inflammatory [30], antiseptic [31], antifungal [32,33], antioxidant [34,35] and especially, antiviral effect against hepatitis B [36] and H1N1 [37]. Recently, CUR has shown great potential as a PS for PDI because of its ability to absorb light, especially in the blue spectral region $[21,23,38,39]$. The low penetration depth of the blue wavelength into tissues also points out that CUR would be a suitable PS for oral superficial decontamination. Unlike the phenothiazine dyes, which have been massively investigated for PDI, the staining of teeth, aesthetic tooth restorations and oral mucosa is improbable after using CUR. For those reasons, the efficacy of PDI-mediated by CUR against microorganisms in saliva needs to be evaluated. Most of the microorganisms in saliva are bound to oral epithelial cells [40], so the response to photodynamic action may change from the effect during in vitro situations [41,42].

Apart from its efficacy, CUR has poor aqueous solubility and bioavailability and constant investigations have suggested some possible ways to increase its biopharmaceutical properties [43]. One such approach can be the use of a water-soluble mixture of CUR and others curcuminoids (Curcumin, Desmethoxy curcumin and Bis-Desmethoxy curcumin). Thus, in an attempt to minimize the amount of pathogens in human saliva and thus decrease the contamination risk of dental staff and patients, the use of PDI for mouth decontamination is proposed. The study assessed the efficacy of a water-soluble mixture of curcuminoids (CRM), previously validated by Rego-Filho et al. [44] in 2014 in reducing the viability of microorganisms found in human saliva.

\section{Material and methods}

\subsection{Study design}

This was a blind, in vitro, experimental study (FOAr Research Ethics Committee-Case number: 68/10). The colony forming units per milliliter $(\mathrm{CFU} / \mathrm{mL})$ was the response variable. The decontami-

\begin{tabular}{|c|c|c|c|}
\hline \multicolumn{4}{|c|}{ Single Treatments Groups } \\
\hline $\operatorname{CUR}(\mathrm{g} / \mathrm{L})$ & Light $\left(J / \mathrm{cm}^{2}\right)$ & CLX & Group \\
\hline $1.5(1 \mathrm{~min})$ & - & - & $\mathrm{C}_{1.5 / 1}$ \\
\hline $1.5(5 \mathrm{~min})$ & - & - & $\mathrm{C}_{1.5 / 5}$ \\
\hline $3.0(1 \mathrm{~min})$ & - & - & $\mathrm{C}_{3.0 / 1}$ \\
\hline $3.0(5 \mathrm{~min})$ & - & - & $\mathrm{C}_{3.0 / 5}$ \\
\hline- & 1.8 & - & $\mathrm{L}_{1.8}$ \\
\hline- & 9.0 & - & $\mathrm{L}_{9.0}$ \\
\hline- & - & $0.12 \%(1 \mathrm{~min})$ & $\mathrm{CLX}_{1}$ \\
\hline- & - & $0.12 \%(5 \mathrm{~min})$ & $\mathrm{CLX}_{5}$ \\
\hline- & - & - & $\mathrm{CTR}_{1}{ }^{*}$ \\
\hline- & - & - & $\mathrm{CTR}_{5}{ }^{*}$ \\
\hline \multicolumn{4}{|c|}{ PDI Groups } \\
\hline $\operatorname{CUR}(\mathrm{g} / \mathrm{L})$ & Light $\left(J / \mathrm{cm}^{2}\right)$ & CLX & Group \\
\hline 1.5 & 1.8 & - & $\mathrm{C}_{1.5} \mathrm{~L}_{1.8}$ \\
\hline 1.5 & 9.0 & - & $\mathrm{C}_{1.5} \mathrm{~L}_{9.0}$ \\
\hline 3.0 & 1.8 & - & $\mathrm{C}_{3.0} \mathrm{~L}_{1.8}$ \\
\hline 3.0 & 9.0 & - & $\mathrm{C}_{3.0} \mathrm{~L}_{9.0}$ \\
\hline
\end{tabular}

Chart 1. Treatment groups.

${ }^{*} \mathrm{CTR}_{1}$ and $\mathrm{CTR}_{5}$ refer to control groups in which samples received only saline solution during 1 and $5 \mathrm{~min}$, respectively.

nation treatment was the independent variable which resulted in the 14 study groups $(n=6)$ that are described in Chart 1 .

\subsection{Representative oral microbiota}

The present study used representative samples of aerobic species commonly found in the human oral cavity. For this purpose, a saliva sample was obtained from pre-selected volunteers from the Araraquara Dental School (UNESP- Univ Estadual Paulista, Brazil). The volunteers were selected following these criteria: no signs and symptoms of disease, non-alcoholic, non-smoker, must be over 18 years of age, not using antibiotics or other mouthwashes, had not used antibiotics in the last month, not using toothpaste with antimicrobial activity and have not been submitted to dental prophylaxis in the last week. A sample of $10 \mathrm{~mL}$ of non-stimulate volunteerís saliva was collected in a sterile $50 \mathrm{~mL}$ Falcon tube to perform the tests.

\subsection{Treatments}

The photosensitizer chosen was a water-soluble mixture of three curcuminoids (curcumin, desmethoxy curcumin and Bisdesmethoxy curcumin; $\mathrm{C}_{33} \mathrm{H}_{50} \mathrm{O}_{16}, 730.32 \mathrm{~g} / \mathrm{mol}$ )(PDT Pharma, Cravinhos, SP, Brazil) which is a topical preparation with acceptable stability and solubility of the curcumin derivatives (Fig. 1). A stock solution of the photosensitizer $(3.0 \mathrm{~g} / \mathrm{L})$ was used and also diluted in distilled water to obtain the concentration of $1.5 \mathrm{~g} / \mathrm{L}$. The CRM was filtered through a sterile membrane with a $0.22 \mu \mathrm{M}$ pore and was prepared immediately before use.

A light emitting diode (LED) device containing 54 blue LEDs $(440 \mathrm{~nm} \pm 10 \mathrm{~nm})$ was used to excite the CRM. This equipment, called "Biotable", provides uniform emission of light in which the lamps (1W) were arranged to simultaneously irradiate an entire 


\section{A: Natural Curcumin}<smiles>COc1cc(/C=C/C(=O)CC(=O)/C=C/c2ccc(O)c(OC)c2)ccc1O</smiles>

\section{B: Water-soluble Mixture of Curcuminoids}

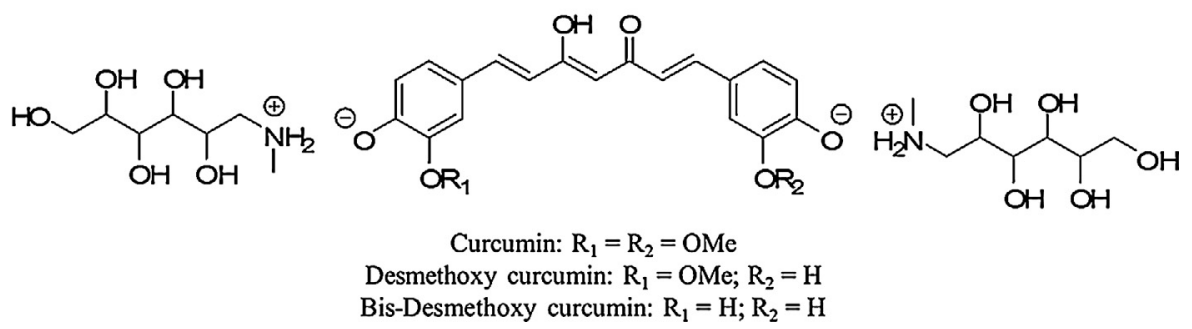

Fig. 1. Chemical structures of the natural curcumin and the mixture of curcuminoids used in the study.

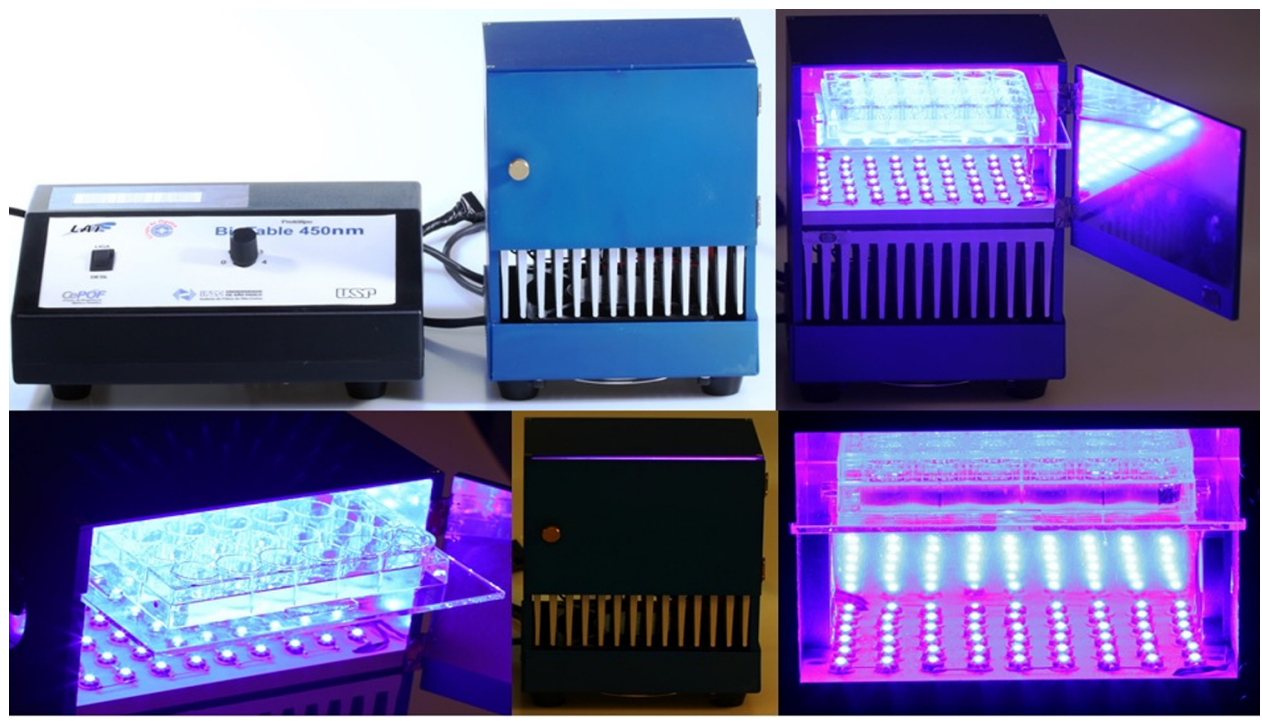

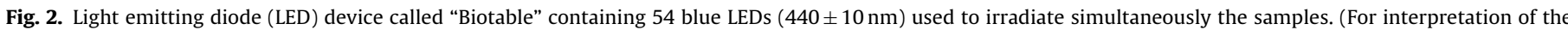
references to colour in this figure legend, the reader is referred to the web version of this article.)

plate well (Fig. 2). The power density of $30 \mathrm{~mW} / \mathrm{cm}^{2}$ was used, and the fluences were $1.8 \mathrm{~J} / \mathrm{cm}^{2}$ and $9 \mathrm{~J} / \mathrm{cm}^{2}$.

The present study used CLX at $0.12 \%$ (Riohex $0.12 \%$-Rioquímica, São José do Rio Preto, SP-Brazil) as a positive control group.

Samples were prepared using $9 \mathrm{~mL}$ of saline (sodium chloride $0.85 \%-\mathrm{SAL}$ ) and $1 \mathrm{~mL}$ of saliva. Aliquots of $500 \mu \mathrm{L}$ were pipetted into well plates. Next, the same volume of the test substances (CLX 0,12\%; CRM $1.5 \mathrm{~g} / \mathrm{L}$; CRM $3.0 \mathrm{~g} / \mathrm{L} ; \mathrm{SAL}$ ) were added and the plates were left in the dark (singles treatments groups) or illuminated (PDI groups) for 1 and 5 min (Fig. 3).

After each treatment, $100 \mu \mathrm{L}$ of each well's contents were serially diluted and plated in petri dishes containing blood agar (BHI-Brian Heart Infusion supplemented with defibrinated sheep blood) using the drop technique. The plates were incubated $\left(37 \pm 1^{\circ} \mathrm{C}\right.$ for $48 \mathrm{~h}$ ) in microaerophilic conditions and the colonies were counted (Fig. 4).

\subsection{Statistical analyses}

Colonies forming units per milliliter $(\mathrm{CFU} / \mathrm{mL})$ were $\log _{10^{-}}$ transformed. After descriptive analysis, a One-way Analysis of Variance with Welch correction for unequal variances was performed, followed by the Games Howell's test of multiple comparisons $(\alpha=0.05)$. CLX 5 data was not included in the ANOVA calculations since no variance was found in this group. Log reduction (LR) measure for antimicrobial efficacy was also calculated [45] using data from the CTR5 as untreated samples.

\section{Results}

All PDI groups showed a significant reduction in $\log _{10}(\mathrm{CFU} / \mathrm{mL})$ compared to the control groups and those groups that used light alone (Fig. 5). The use of $3.0 \mathrm{~g} / \mathrm{L}$ of CRM with $9.0 \mathrm{~J} / \mathrm{cm}^{2}$ was the most effective PDI protocol, achieving a mean LR of 2.54 (Table 1). 


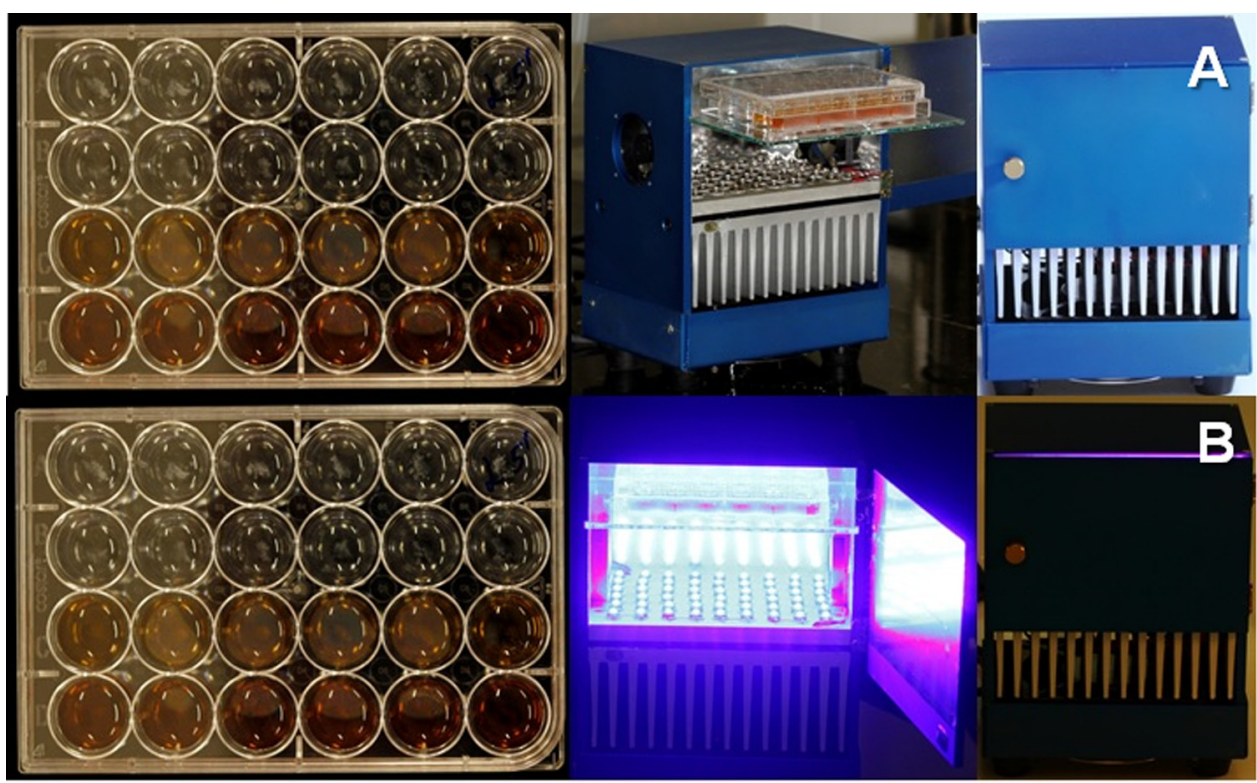

Fig. 3. In "A", samples without LED light irradiation and in "B", samples that recieved LED light irradiation.

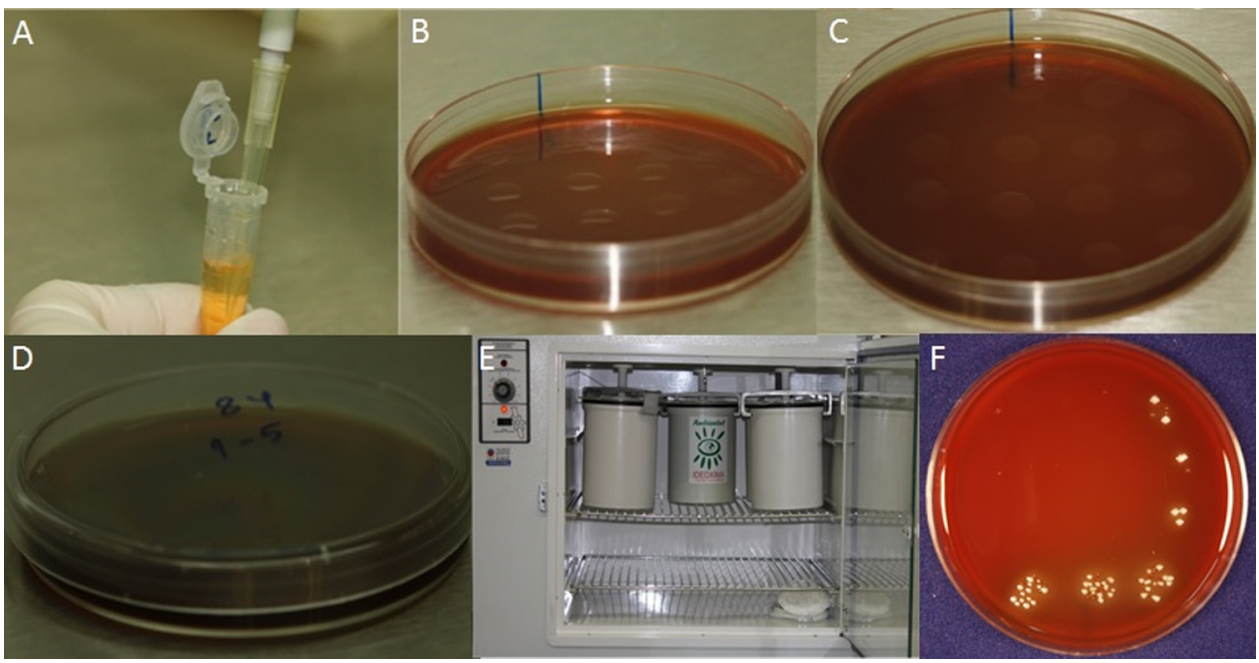

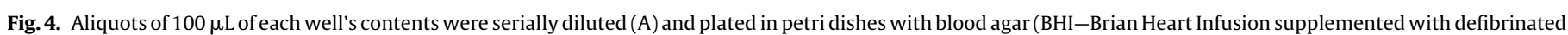
sheep blood), using the drop technique (B-D). The plates were incubated ( $37 \pm 1^{\circ} \mathrm{C}$ for $48 \mathrm{~h}$ ) in microaerophilic conditions (E) and the colonies were counted (F).

Table 1

Average log reduction (LR) and respective standard deviation (SDLR) obtained after antimicrobial treataments. Data from CTR5 was used as untreated samples.

\begin{tabular}{lrc}
\hline Group & \multicolumn{1}{c}{ LR } & SD $_{\text {LR }}$ \\
\hline L1.8 & -0.03 & 0.12 \\
L9.0 & -0.07 & 0.12 \\
C1.5/1 & 0.39 & 0.13 \\
C1.5/5 & 0.81 & 0.12 \\
C3.0/1 & 1.56 & 0.15 \\
C3.0/5 & 1.74 & 0.13 \\
CLX1 & 3.04 & 0.18 \\
CLX5 & 6.89 & 0.12 \\
C1.5L1.8 & 0.74 & 0.15 \\
C1.5L9.0 & 1.89 & 0.13 \\
C3.0L1.8 & 1.55 & 0.20 \\
C3.0L9.0 & 2.54 & 0.16 \\
\hline
\end{tabular}

However, the additional PDI groups, $\mathrm{C}_{3.0} \mathrm{~L}_{1.8}, \mathrm{C}_{1.5} \mathrm{~L}_{9.0}$, and $\mathrm{C}_{1.5} \mathrm{~L}_{1.8}$ showed similar antimicrobial effect of using the CRM without light.

The use of CLX at $0.12 \%$ for 5 min resulted in the total absence of colonies in the six samples analyzed. When used for $1 \mathrm{~min}$, its antimicrobial effect was similar to the PDI using $3.0 \mathrm{~g} / \mathrm{L}$ of CRM with $9.0 \mathrm{~J} / \mathrm{cm}^{2}$ of illumination $\left(\mathrm{C}_{3.0} \mathrm{~L}_{9.0}\right)$.

Light alone showed no significant effect on colonies viability.

\section{Discussion}

In order to avoid the biological risks that patients and dental team are exposed during clinical routine, the decontamination of the patients' mouth was advocated. The present study investigated the potential of a curcuminoid-based compound, with an increased aqueous solubility as a PS against bacteria in saliva. According to the results, PDI significantly reduced microorganisms viability in all protocols investigated and the highest reduction found was 2.54 logs. Others studies have evaluated PDI using the same compound and the findings, regarding the efficacy, corroborates with ours $[38,46,47]$. However, these were in vitro studies that did not assess the efficacy of the therapy against microorganisms within a nutritional medium such as saliva. 


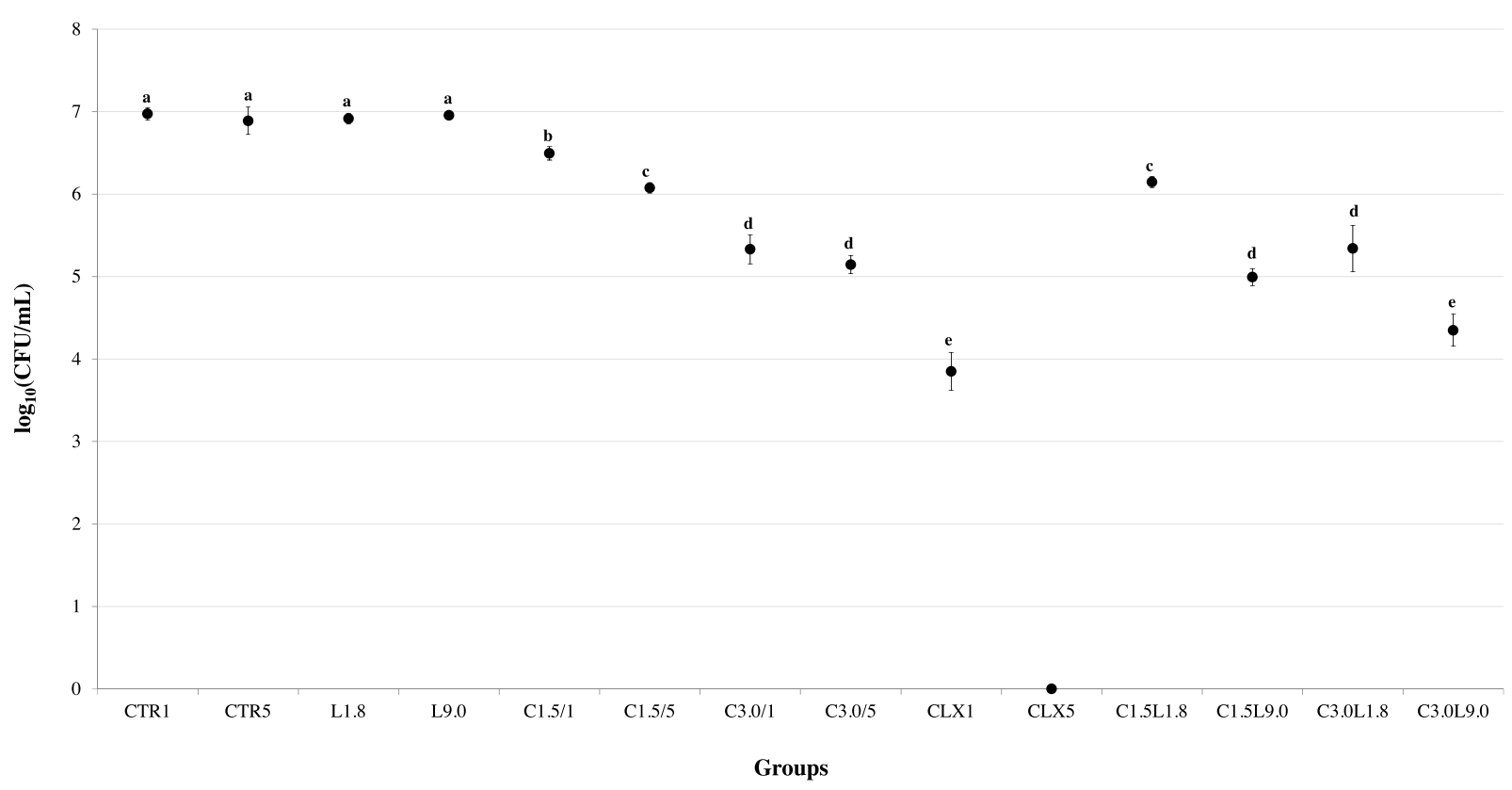

Fig. 5. Antimicrobial effect of PDI (Photodynamic inactivation) with blue LED (light emitting diode) as oral desinfection method.

Tonon et al. [38] evaluated the in vitro susceptibility of standard and clinical isolates of Streptococcus mutans to CRM-PDI using different light fluences. The most effective fluence was $48 \mathrm{~J} / \mathrm{cm}^{2}$, which induced photoinactivation of both the standard strain $(7.48-2.16 \log )$ and the clinical isolate $(10.24-6.77 \mathrm{log})$. It was interesting to note that, independent of the CRM concentration and fluence used, the log reduction obtained for the clinical isolate was lower compared to the standard strain. Another study already suggested that clinical strains are normally more resistant to PDI than the laboratory strains [33]. Therefore, our results may contribute a little more to the advancement of PDI, since it investigated its efficacy against clinical strains on saliva samples. Another investigation [48], showed a viability reduction of $99.99 \%$ and $37.6 \%$ for S. mutans and Lactobacillus acidophilus, respectively, after the use of $1.5 \mathrm{~g} / \mathrm{L}$ of CRM associated with blue led light $\left(19 \mathrm{~mW} / \mathrm{cm}^{2}\right)$. The higher efficacy of CRM-mediated PDI showed by these authors can be due to the in vitro design, coupled with the use of standard strains and different physiological states of micro-organisms. Additionally, a direct comparison with our findings is difficult to make since they used the survival fraction instead of log reduction to describe their results. Most investigations on PDI efficacy assessed samples containing single species in planktonic or biofilm form [32,47-49]. However, the clinical effectiveness of PDI will depend on the therapy's ability to eliminate the microorganisms within its natural environment. In fact, studies have shown that the efficacy in microorganism elimination is reduced in saliva compared to their in vitro planktonic counterparts $[37,50]$, because saliva can function as a barrier to the antimicrobial effect. Thus, the results of the present investigation will contribute to the future of clinical PDI disinfection since it showed that CRM-mediated PDI was capable of reducing the viability of general oral microflora in saliva.

Natural CUR has showed higher in vitro efficacy against oral microorganism in previous investigations [32,33,49,50]. Due to the low solubility of pure CUR, those studies used a polar aprotic solvent (dimethyl sulfoxide, DMSO) to prepare standard solutions of the PS prior to illumination. Bruzell et al. [51] in 2005 suggested that the phototoxic effects induced by CUR can be highly dependent on the type of preparation used. The polar solvent used previously is able to rapidly penetrate through the biological membranes and cellular barriers, probably by producing structural defects in the membrane
[52]. This fact can possibly justify the differences found between the results [53,54]. Because DMSO is not an optimal vehicle for in vivo applications [51,52], further studies should evaluate different vehicles as efficient as DMSO for curcumin to exert photokilling against bacterial strains. An ideal photosensitizer should have low toxicity to host cells and high toxicity to the target cells when activated by the light, thereby higher CRM concentrations could improve the effect of PDI. Additionally, since CRM is a soluble compound and because it has been previously validated as PS, the use of solvent is not necessary, which is an advantage for clinical use, justifying further studies with this compound [44].

While there was no significant difference between the $\mathrm{C}_{1.5} \mathrm{~L}_{9.0}$ ( $\mathrm{IC}_{95 \%}: 4.99 \pm 0.27$ ) and $\mathrm{C}_{3.0} \mathrm{~L}_{1.8}$ ( $\mathrm{IC}_{95 \%}: 5.34 \pm 0.81$ ) groups, the $\mathrm{C}_{3.0} \mathrm{~L}_{9.0}$ ( $\mathrm{IC}_{95 \%}: 4.35 \pm 0.52$ ) groups showed higher photodynamic efficacy. Both the PDI $\left(\mathrm{C}_{3.0} \mathrm{~L}_{9.0}\right)$ and $\mathrm{CHX}_{1}$ groups had similar antimicrobial effects, reducing approximately 2.54 logs and 3.04 logs, respectively. The $\mathrm{CLX}_{5}$ increased microbial inactivation since the total elimination of microorganisms from the saliva samples was observed. Several investigations have shown that CLX can be an extremely effective antimicrobial agent against Gram-positive and Gram-negative bacteria, being currently considered the gold standard for oral decontamination [8-10]. However, the constant use of CLX can promote changes in taste and brownish pigmentation on the teeth, restorations and tongue [6,8,9]. Additionally, 5 min of mouthwash can be uncomfortable for the patient and the longer the exposure time to CLX, the higher the collateral effects largely described in the literature. Thus, our results indicate that the use of PDI may be preferable since a similar efficacy to CLX 1 was found and no adverse effect on taste or teeth color have been reported, as well as no resistance development $[16,17,32,50,55,56]$.

Many different photosensitizing agents have also been studied over the years [38]. Phenothiazine methylene blue (MB) has shown excellent photochemical properties and is recognized as a non-toxic dye, so that it can be administrated topically and orally. In addition, MB has a natural antifungal and antibacterial activity [57]. Rolim et al. [28] evaluated the antimicrobial activity of MBmediated PDI using $24 \mathrm{~J} / \mathrm{cm}^{2}$ of light and the results showed no effect against $S$. mutans in a planktonic culture $(\mathrm{p}=0.62)$, concluding that MB-mediated PDI is not an optimal choice for reducing S. mutans. On the other hand, others studies related that MB as 
a photosensitizer agent was effective against the Candida species whether grown planktonically or in a biofilm form $[38,58,59]$. This difference between bacteria and fungi might occur because of the cellular structure [38]. However, it is important to highlight that the described studies were performed on reference strains, which is known to be more susceptible than clinical isolates. Additionally, the clinical use of MB for general oral decontamination may have some drawbacks, such as teeth and restorative pigmentation and its low efficacy against intracellular viruses [57].

CRM per se also showed antibacterial efficacy, but this was observed only at the highest concentrations $\left(C_{3.0 / 1}\right.$ and $\left.C_{3.0 / 5}\right)$. This was probably due to the increased drug concentration and time that the inoculum was exposed to CRM. Even though the results showed some dark toxicity of CRM, it is important to highlight that the greatest antimicrobial effect (2.54 log reduction) was achieved when CRM was irradiated with blue LED light. CRM phototoxicity seems to be mediated by the excited states of CRM and/or products derived from the subsequent reactions with oxygen during irradiation [16,56,60]. As described above, CRM per se promoted antibacterial effects and it is important to accentuate that, in order to perform oral disinfection, the effect of CRM would improve enhanced by light. Light alone $\left(\mathrm{L}_{1.8}\right.$ and $\left.\mathrm{L}_{9.0}\right)$ had no effect on microorganism viability (Mean $\pm \mathrm{IC}_{95 \%}$ : $6.92 \pm 0.17$ and $6.95 \pm 0.14$, respectively). This was expected because, in general, the light potential for pathogen reduction is not observed [32,33,60-63]. Others studies, such as Araujo et al. [50] in 2012, obtained the same results for LED alone (Fig. 4) [25,32,33,49,60,61,63].

The present study indicates that CRM-mediated PDI has great potential and can be useful for oral or surface decontamination in dental care conditions, but the technique needs to be further improved for clinical use, because the future of PDI will depend on the interactions between clinical applications and technological innovations [44]. Furthermore, this investigation was important because, unlike many studies that assess microbial species in an isolated form, the present study investigated the oral microbiota in saliva in order to simulate the clinical environment. In addition, the PDI technique can be used with success in place of CLX in patients that are sensitive to some CLX compounds, or who do not want the side effects caused by CHX: staining of teeth and tongue, taste modification and mucosal desquamation.

\section{References}

[1] A. Al Maghlouth, Y. Al Youself, N. Al Bagieh, Qualitative and quantitative analysis of bacterial aerosols, J. Contemp. Dent. Pract. 15 (4) (2004) 91-100.

[2] C.D. Bentley, N.W. Burkhart, J.J. Crawford, Evaluating spatter and aerosol contamination during dental procedures, J. Am. Dent. Assoc. 125 (5) (1994) 579-584.

[3] V.L.S. Resende, M.H.G. Abreu, S.M. Paiva, R. Teixeira, I.A. Pordeus, Factors associated with seroprevalence of hepatitis $\mathrm{C}$ among dentists at a large Brazilian city, Virol. J. 6 (1) (2009) 228.

[4] P.A. Leggat, U. Kedjarune, Bacterial aerosols in the dental clinic: a review, Int. Dent. J. 51 (1) (2001) 39-44.

[5] R. Rautemaa, A. Nordberg, K. Wuolijoki-Saaristo, J.H. Meurman, Bacterial aerosols in dental practice-a potential hospital infection problem? J. Hosp. Infect. 64 (1) (2006) 76-81.

[6] T.A.D.V. Semenoff, A. Semenoff Segundo, E.R. Biasolli, D.G. Bernabé, A.F. Bosco, V.G. Garcia, et al., Effectiveness of $0,12 \%$ and $2 \%$ chlorhexidine stored at different temperatures on some microorganisms in vitro, R. Periodontol. 18 (2) (2008) 49-54.

[7] H. Hoshijima, N. Kuratani, R. Takeuchi, T. Shiga, E. Masaki, K. Doi, et al., Effects of oral hygiene using chlorhexidine on preventing ventilator-associated pneumonia in critical-care settings: a meta-analysis of randomized controlled trials, J. Dent. Sci. 8 (4) (2013) 348-357.

[8] G.E. Davies, 1:6-Di-4'-chlorophenyldiguanidohexane (hibitane). Laboratory investigation of a new antibacterial agent of a high potence, Br. J. Pharmacol Chemoter. 9 (2) (1954) 192-196.

[9] J.R. Siqueira, Effectiveness of four chemical solutions in eliminating Bacillus subtilis spores on gutta percha cones, Endod. Dent. Traumatol. 14 (3) (1998) $124-126$.

[10] E.G.O. Mima, A.C. Pavarina, F.S. Vargas, E.T. Giampaolo, A.L. Machado, C.E. Vergani, Effectiveness of chlorhexidine on the disinfection of complete dentures colonized with fluconazole-resistant Candida albicans: in vitro study, Mycoses 54 (5) (2010) 506-512.

[11] K.A.R.V. Prasad, S. John, V. Deepika, K.S. Dwijendra, B.R. Reddy, S. Chincholi, Anti-Plaque efficacy of herbal and $0.2 \%$ chlorhexidine gluconate mouthwash: a comparative study, J. Int. Oral Health 7 (8) (2015) 98-102.

[12] D.G. Ribeiro, A.C. Pavarina, L.N. Dovigo, E.G.O. Mima, A.L. Machado, V.S. Bagnato, et al., Photodynamic inactivation of microorganisms present on complete dentures: a clinical investigation, Lasers Med. Sci. 27 (1) (2012) $161-168$

[13] F. Vohra, Z. Akram, S.H. Safi, R. Devi Vaithilingam, A. Ghanem, K. Sergis, et al., Role of antimicrobial photodynamic therapy in the treatment of aggressive periodontitis: a systematic review, Photodiagnosis Photodyn. Ther. 13 (2016) 139-147 (Article in press).

[14] H. Gursoy, C. Ozcakir-Tomruk, J. Tanalp, S. Yilmaz, Photodynamic therapy in dentistry: a literature review, Clin. Oral Investig. 17 (4) (2013) 1113-1125.

[15] F. Javed, L.P. Samaranayake, G.E. Romanos, Treatment of oral fungal infections using antimicrobial photodynamic therapy: a systematic review of currently available evidence, Photochem. Photobiol. Sci. 13 (5)(2014) 726-734.

[16] M. Wainwright, Photodynamic antimicrobial chemotherapy (PACT), J. Antimicrob. Chemother. 42 (1) (1998) 13-28

[17] F.P. Gonzales, T. Maisch, Photodynamic inactivation of microorganisms as an innovative approach to kill mucocutaneous and skin microorganisms, G. Ital. Dermatol. Venereol. 145 (4) (2010) 477-489.

[18] M.R. Hamblin, T. Hasan, Photodynamic therapy: a new antimicrobial approach to infectious disease? Photochem. Photobiol. Sci. 3 (5) (2004) 436-450.

[19] R.F. Donnelly, P.A. McCarron, M.M. Tunney, Antifungal photodynamic therapy, Microbiol. Res. 163 (1) (2008) 1-12.

[20] C.C. Quishida, E.G. Mima, L.N. Dovigo, J.H. Jorge, V.S. Bagnato, A.C. Pavarina, Photodynamic inactivation of a multispecies biofilm using Photodithazine $\left({ }^{\circledR}\right)$ and LED light after one and three successive applications, Lasers Med. Sci. 30 (9) (2015) 2303-2312.

[21] L.N. Dovigo, J.C. Carmello, C.A. de Souza Costa, C.E. Vergani, I.L. Brunetti, V.S Bagnato, et al., Curcumin-mediated photodynamic inactivation of Candida albicans in a murine model of oral candidiasis, Med. Mycol. 51 (3) (2013) $243-251$

[22] E.G. Mima, A.C. Pavarina, D.G. Ribeiro, L.N. Dovigo, C.E. Vergani, V.S. Bagnato, Effectiveness of photodynamic therapy for the inactivation of Candida spp. on dentures: in vitro study, Photomed Laser Surg. 29 (12) (2011) 827-833.

[23] A.P. Ribeiro, M.C. Andrade, F. da Silva Jde, J.H. Jorge, F.L. Primo, A.C. Tedesco, et al., Photodynamic inactivation of planktonic cultures and biofilms of Candida albicans mediated by aluminum-chloride-phthalocyanine entrapped in nanoemulsions, Photochem. Photobiol. 89 (1) (2013) 111-119.

[24] T.W. Wong, H.J. Huang, Y.F. Wang, Y.P. Lee, C.C. Huang, C.K. Yu, Methylene blue-mediated photodynamic inactivation as a novel disinfectant of enterovirus 71, J. Antimicrob. Chemother. 65 (2010) 2176-2182.

[25] F. Foschi, C.R. Fontana, K. Ruggiero, R. Riahi, A. Vera, A.G. Doukas, et al., Photodynamic inactivation of enterococcus faecalis in dental root canals in vitro, Lasers Surg. Med. 39 (10) (2007) 782-787

[26] I.M. Bevilacqua, R.A. Nicolau, S. Khouri, A. Brugnera Jr., G.R. Teodoro, R.A. Zângaro, et al., The impact of photodynamic therapy on the viability of Streptococcus mutans in a planktonic culture, Photomed. Laser Surg. 25 (6) (2007) 513-518.

[27] I.C.J. Zanin, R.B. Gonçalves, A. Brugnera Junior, C.K. Hope, J. Pratten, Susceptibility of Streptococcus mutans biofilms to photodynamic therapy: an in vitro study, J. Antimicrob. Chemother. 56 (2) (2005) 324-330.

[28] J.P.M.L. Rolim, M.A. de-Melo, S.F. Guedes, F.B. Albuquerque-Filho, J.R. de Souza, N.A.P. Nogueira, et al., The antimicrobial activity of photodynamic therapy against Streptococcus mutans using different photosensitizers, J. Photochem. Photobiol. B. 106 (1) (2012) 40-46.

[29] A. Downham, P. Collins, Colouring our foods in the last and next millennium, Int. J. Food Sci. Technol. 35 (1) (2000) 5-22.

[30] J. Epstein, I.R. Sanderson, T.T. Macdonald, Curcumin as a therapeutic agent: the evidence from in vitro, animal and human studies, Br. J. Nutr. 103 (11) (2010) 1545-1557.

[31] T.A. Dahl, W.M. McGowan, M.A. Shand, V.S. Srinivasan, Photokilling of bacteria by the natural dye curcumin, Arch. Microbiol. 151 (2) (1989) 183-185

[32] L.N. Dovigo, A.C. Pavarina, A.P. Ribeiro, I.L. Brunetti, C.A. Costa, D.P. Jacomassi, et al., Investigation of the photodynamic effects of curcumin against Candida albicans, Photochem. Photobiol. 87 (4) (2011) 895-903.

[33] L.N. Dovigo, A.C. Pavarina, J.C. Carmello, A.L. Machado, I.L. Brunetti, V.S. Bagnato, et al., Susceptibility of clinical isolates of Candida to photodynamic effects of Curcumin, Lasers Surg. Med. 43 (9) (2011) 927-934.

[34] G.K. Jayaprakasha, L. Jaganmohan Rao, K.K. Sakariah, Antioxidants activities of curcumin, demetoxycurcumin and bisdemetoxycurcumin, Food Chem. 98 (4) (2006) 720-724

[35] H.H. Tonnesen, H. de Vries, J. Karlsen, G. Beijersbergen van Henegouwen, Studies on curcumin and curcuminoids. IX: investigation of the photobiological activity of curcumin using bacterial indicator systems, J. Pharm. Sci. 76 (5) (1987) 371-373.

[36] H. Jin Kim, H. Seung Yoo, J. Chul Kim, C. Su Park, M. Sun Choi, M. Kim, et al., Antiviral effect of Curcuma longa Linn extract against hepatitis B virus replication, J. Ethnopharmacol. 124 (2) (2009) 189-196.

[37] D.-Y. Chen, J.-H. Shien, L. Tiley, S.-S. Chiou, S.-Y. Wang, T.-J. Chang, et al., Curcumin inhibits influenza virus infection and haemagglutination activity, Food Chem. 119 (4) (2010) 1346-1351. 
[38] C.C. Tonon, M.A. Paschoal, M. Correia, D.M. Spolidório, V.S. Bagnato, J.S. Giusti, L. Santos-Pinto, Comparative effects of photodynamic therapy mediated by curcumin on standard and clinical isolate of Streptococcus mutans, J. Contemp. Dent. Pract. 16 (1) (2015) 1-6.

[39] M.F. da Frota, J.M. Guerreiro-Tanomaru, M. Tanomaru-Filho, V.S. Bagnato, C.G. Espir, F.L. Berbert, Photodynamic therapy in root canals contaminated with Enterococcus faecalis using curcumin as photosensitizer, Lasers Med. Sci. 30 (7) (2015) 1867-1872.

[40] C. Dawes, Salivary flow patterns and the health of hard and soft oral tissues, J. Am. Dent. Assoc. 139 (2) (2008) 18S-24S

[41] M. Wilson, Lethal photosensitisation of oral bacteria and its potential application in the photodynamic therapy of oral infections, Photochem. Photobiol. Sci. 3 (5) (2004) 412-418.

[42] S. Sarkar, M. Wilson, Lethal photosensitization of bacteria in subgingival plaque from patients with chronic periodontitis, J. Periodontal Res. 28 (3) (1993) 204-210.

[43] S. Prasad, A.K. Tyagi, B.B. Aggarwal, Recent developments in delivery, bioavailability, absorption and metabolism of curcumin: the golden pigment from golden spice, Cancer Res. Treat. 46 (1) (2014) 2-18.

[44] F.G. Rego-Filho, M.T. de Araujo, K.T. de Oliveira, V.S. Bagnato, Validation of photodynamic action via photobleaching of a new curcumin-based composite with enhanced water solubility, J. Fluoresc. 24 (5) (2014) 1407-1413.

[45] Hamilton M.A. KSA-SM-07-The log reduction (LR) measure of disinfectant efficacy. Knowledge Sharing Articles, Center for Biofilm Engineering at Montana State University, Bozeman, MT. November 17, 2010 [E-publication].

[46] N.C. Araújo, C.R. Fontana, V.S. Bagnato, M.E.M. Gerbi, Photodynamic antimicrobial therapy of curcumin in biofilms and carious dentine, Lasers Med. Sci. 29 (2) (2014) 629-635.

[47] M.A. Paschoal, C.C. Tonon, D.M.P. Spolidório, V.S. Bagnato, J.S.M. Giusti, L. Santos-Pinto, Photodynamic potential of curcumin and blue LED against Streptococcus mutans in a planktonic culture, Photodiag. Photodyn. Ther. 10 (3) (2013) 313-319.

[48] N.C. Araújo, C.R. Fontana, V.S. Bagnato, M.E.M. Gerbi, Photodynamic effects of curcumin against cariogenic pathogens, Photomed. Laser Surg. 30 (7) (2012) 393-399.

[49] A.P. Ribeiro, A.C. Pavarina, L.N. Dovigo, I.L. Brunetti, V.S. Bagnato, C.E. Vergani, C.A. Costa, Phototoxic effect of curcumin on methicillin-resistant Staphylococcus aureus and L929 fibroblasts, Lasers Med. Sci. 28 (2) (2013) 391-398.
[50] N.C. Araújo, C.R. Fontana, M.E.M. Gerbi, V.S. Bagnato, Overall-mouth disinfection by photodynamic therapy using curcumin, Photomed. Laser Surg. 30 (2) (2012) 96-101.

[51] E.M. Bruzell, E. Morisbak, H.H. Tønnesen, Studies on curcumin and curcuminoids. XXIX. Photoinduced cytotoxicity of curcumin in selected aqueous preparations, Photochem. Photobiol. Sci. 4 (7) (2005) 523-530.

[52] T.J. Anchordoguy, J.F. Carpenter, J.H. Crowe, L.M. Crowe Temperature-dependent perturbation of phospholipid bilayers by dimethylsulfoxide, Biochim. Biophys. Acta 1104 (1) (1992) 117-122.

[53] C.F. Chignell, P. Bilskj, K.J. Reszka, A.G. Motten, R.H. Sik, T.A. Dahl, Spectral and photochemical properties of curcumin, Photochem. Photobiol. 59 (3) (1994) 295-302.

[54] D. Patra, C. Barakat, Synchronous fluorescence spectroscopic study of solvatochromic curcumin dye, Spectrochim. Acta A 79 (5) (2011) 1034-1041.

[55] N.S. Soukos, M. Wilson, T. Burns, P.M. Speight, Photodynamic effects of toluidine blue on human oral keratinocytes and fibroblasts and Streptococcus sanguis evaluated in vitro, Lasers Surg. Med. 18 (3) (1996) 253-259.

[56] R.R. Allison, V.S. Bagnato, R. Cuenca, G.H. Downie, C.H. Sibata, The future of photodynamic therapy in oncology, Future Oncol. 2 (1) (2006) 53-71.

[57] M. Wainwright, K.B. Crossley, Methylene blue-a therapeutic dye for all seasons? J. Chemother. 14 (5) (2002) 431-443.

[58] S.C. De Souza, J.C. Junqueira, I. Balducci, C.Y. Koga-Ito, Photosensitisation of different Candida species by low power laser light, J. Photochem. Photobiol. B: Biol. 83 (1) (2006) 34-38.

[59] M. Wilson, N. Mia, Sensitisation of Candida albicans to killing by low-powe laser light, J. Oral Pathol. Med. 22 (8) (1993) 354-357.

[60] N.S. Soukos, J.M. Goodson, ynamic therapy in the control of oral biofilms, Periodontol. 200055 (1) (2011) 143-166.

[61] C.R. Fontana, A.D. Abernathy, S. Som, K. Ruggerio, S. Doucette, R.C. Marcantonio, et al., The antibacterial effect of photodynamic therapy in dental plaque-derived biofilms, J. Periodontal Res. 44 (6) (2009) 751-759.

[62] M. Wilson, Lethal photosensitization of oral bacteria and its potential application in the photodynamic therapy of oral infections, Photochem. Photobiol. Sci. 3 (5) (2004) 412-418.

[63] S. Wood, B. Nattress, J. Kirkham, R. Shore, S. Brookes, J. Griffiths, et al., An in vitro study of the use of photodynamic therapy for the treatment of natural oral plaque biofilms formed in vivo, J. Photochem. Photobiol. B 50 (1) (1999) $1-7$. 